\title{
HUERTA DE VALENCIA: ENTRE LA COLECCIÓN DE NOVELAS Y EL CANCIONERO DE ACADEMIA
}

\author{
MARCial Rubio Árquez \\ Università degli Studi “G. d'Annunzio" di Chieti-Pescara \\ arquez@unich.it
}

$\mathrm{E}$ n una producción editorial como la de Castillo Solórzano conviene moverse con norte seguro para no perderse en juicios consabidos y precipitadas valoraciones. Se trata, como sabemos, de una obra tan vasta como variada, cuya enumeración, aunque solo se cite de forma genérica y sin títulos, ya impresiona: «cinco novelas largas, diez colecciones de novelas cortas, cuatro libros de biografías y vidas de santos y varias obras teatrales, además de un libro de composiciones poéticas de carácter jocoso» (Velasco Kindelan 1983: 27). Nos las vemos, pues, con un verdadero polígrafo que cultiva todos o casi todos los géneros literarios de su momento (poesía, teatro, prosa), en un claro alarde de suficiencia literaria que intenta mostrarse capaz de satisfacer el paladar literario de todo tipo de lectores. Añádase, para ponderar mejor la necesidad de dicha brújula, que toda esta imponente producción literaria se realizó en solo un cuarto de siglo, en esos veinticinco años que van de su primera obra estampada, la primera parte de los Donayres del Parnaso (Madrid, 1624, 1625) ${ }^{1}$ a su última y seguramente ya póstuma obra, la Sala de recreación, publicada en 1649 en Zaragoza (1977). Con otras palabras: entre 1624 y 1649 Castillo Solórzano fue capaz de escribir y publicar una ingente producción literaria que abarca casi todos los géneros de la época.

A este recorrido literario sucintamente bosquejado se corresponde, con curioso paralelismo, un recorrido vital que no se explica sin la ayuda de aquel ${ }^{2}$. De este modo, si sus primeras obras - las dos partes de los Donaires del Parnaso- son

\footnotetext{
1 Las dos partes pueden ahora leerse en la edición con notas de López Gutiérrez (Castillo Solórzano 2003).

2 La biografía más completa es la de Rafael Bonilla Cerezo (2012), que además relaciona los datos biográficos con los bibliográficos, haciendo así un panorama absolutamente imprescindible para el estudio de Castillo Solórzano.
}

Edad de Oro, XXXVI (2017), pp. 45-58, ISSN: 0212-0429 - DOI http://dx.doi.org/10.15366/edadoro2017.36.003 
una clara muestra de «poesía de academia» ${ }^{3}$, declamada con toda probabilidad en la "Academia de Madrid" (Kennedy 1968: 193), presidida primero por su amigo Sebastián Francisco de Medrano y después, a partir de 1622, por Francisco de Mendoza, y estampadas las dos en Madrid, Francisco Flamenco, 1624 y 1625, respectivamente, las muchas otras que seguirán a continuación presentan literariamente una acomodación a los géneros más en boga, pero también y sobre todo una adaptación editorial al recorrido geográfico y vital de su autor, imprimiéndose consecuencialmente allí donde su devenir biográfico, siempre al amparo de algún gran noble, le llevara. Y así, como digo, se pasa de las primeras obras impresas en Madrid, a continuar - cito sin orden y solo las primeras ediciones- con Sevilla, Valencia, Barcelona, Zaragoza, Madrid, Zaragoza.

Todo lo anterior -por más que sucinta y superficialmente contado- resulta de conocimiento imprescindible, porque la obra que ahora me interesa marca, como intentaré explicar en las siguientes páginas, una etapa no despreciable en ese panorama literario y vital mínimamente bosquejado. Se trata, como anticipaba ya el título de mi trabajo, de la Huerta de Valencia. Prosas y versos en las Academias della, impresa en Valencia por Miguel Sorolla en1629. Es, por un lado, la primera obra que Castillo imprime en Valencia, ciudad a la que se trasladó siguiendo a su nuevo señor, don Luis Fajardo de Requeséns y Zúñiga, marqués de los Vélez y Molina, nombrado virrey el año anterior, en 1628. Y, en efecto, la obra está dedicada a don Pedro Fajardo de Zúñiga, marqués de Molina e hijo del nuevo virrey. Esta primogenitura valenciana se sobreentiende si no olvidamos que también el mismo año y en esta ciudad apareció su Lisardo enamorado, pero que, como ha demostrado sobradamente Giorgi (2014), dicha obra no es más que una reescritura de Escarmientos de amor moralizados, publicada en Sevilla el año anterior, esto es, en 1628.

Parece fácil conjeturar, por lo dicho, que con esta obra Castillo no solo pretendía rendir homenaje literario a su nuevo señor, sino también y sobre todo presentarse ante la intelectualidad literaria valenciana con las debidas credenciales. Si hacemos caso a lo que nos refiere Ruiz Morcuende (Castillo Solórzano 1972: XI), su llegada, en efecto, fue calurosamente acogida por los literatos locales, quienes no solo le invitaron a sus academias, sino que le dejaron participar con su poesía. Lógico, por lo demás, si se piensa que las credenciales literarias a Castillo Solórzano le sobraban, pues además del ya citado cancionero, las dos partes de Donayres del Parnaso de las que hablaré después, nuestro autor había publicado la colección de novelas Tardes entretenidas (Madrid, 1625), donde se incluían seis;

\footnotetext{
Lo que ha llevado a Jauralde Pou (1979: 787) a definir a Castillo Solórzano como un «poeta "académico"». Para las academias literarias del período son imprescindibles, además de trabajos específicos que se citarán después, los de Willard F. King (1960 y 1963), Sánchez (1961) y Aurora Egido (1990).
} 
Jornadas alegres (Madrid, 1626), donde además de otras cinco novelas aparecía el poema jocoso «Fábula de las bodas de Manzanares»; Tiempo de regocijo y Carnestolendas de Madrid (Madrid, 1627), con tres novelitas y un entremés, «El casamentero», y, aceptando que la primera versión es, como ya se ha dicho, de Sevilla (1528), el Lisardo enamorado (Valencia, 1529), en cualquier caso anterior a la nuestra, como indica el mismo Castillo en la dedicatoria «Al lector» ${ }^{4}$. Esta ingente y sorprendente producción literaria venía avalada, además, por la aquiescencia y el aplauso de las principales plumas que por aquel entonces reinaban en el Parnaso castellano. Y para certificar esto baste recordar que ya su primera obra, el cancionero jocoso Donaires del Parnaso, llevaba sendas aprobaciones: la primera, de Tirso de Molina, explicaba que la obra no solo no tenía nada contra la fe y las buenas costumbres, sino que, por el contrario, estaba llena de «agudezas y sales, dignas del ingenio de su autor, y de la estimación que hacen dél en esta Corte todos los buenos ingenios» (Castillo Solórzano 2003: 260). La segunda, de Lope de Vega, insiste en parecidos términos, esto es, el ingenio del autor y el reconocimiento que ha ganado con su poesía: «muestra del vivo ingenio de su autor, que, por estas flores, promete su dueño el fruto. Escribiolas en las Academias desta Corte, donde lucieron con general aplauso y aprobación, así de los que escribieron en ellas como de los señores que las honran» (Castillo Solórzano 2003: 260). Con estos dos astros, pero también con Guillén de Castro, Vélez de Guevara, Mira de Amescua, Quevedo y otros muchos ingenios había coincidido nuestro autor en la Academia de Madrid, por lo que las alabanzas de los dos primeros parecen ir mucho más allá de las habituales e hipócritas aclamaciones entre poetas y, por el contrario, parecen más bien fruto de verdadera admiración y amistad.

Volviendo a la obra, esta suponía, además, un temprano retorno a sus orígenes literarios, al mundo de las academias literarias en las que, como acabamos de ver, Castillo nace como escritor y se hace con un cierto prestigio entre sus pares. Este origen académico se indica ya desde el título de la obra: Huerta de Valencia. Prosas y versos en las Academias de ella, y quizás valga la pena hacer notar la redundancia que se esconde tras tan genérica denominación, pues ya esa mezcla de «prosas y versos», esto es, de cualquier tipo de texto literario, indicaba claramente un origen de literatura de academia, donde, como sabemos, era absolutamente normal la promiscuidad genérica. Evidentemente este retorno a los inicios de su quehacer literario no era casual ni mucho menos inocente, pues es bien sabido que quizás, junto con Madrid, Valencia era la otra gran capital de las academias literarias durante el siglo XVII (Mas i Usó 1991).

\footnotetext{
4 «Este espera en tus manos para que con él se anime a dar a la estampa la Huerta de Valencia, libro de novelas», Lisardo enamorado (1629), f. [3]. Hay edición moderna: Lisardo enamorado (1947), pero considero más fiable consultar el texto original.
} 
La estrategia editorial, que tal era, parecía tan inteligente como estudiada. Sin embargo, y a pesar de la referencia del título, el análisis de la estructura y del contenido arrojan datos que parecen no ajustarse a los preceptos - por lo demás un tanto vagos- de la literatura de academia, ni siquiera como es el caso de esta «ficticia academia», como sagazmente la define Mas i Usó (1994: 51). Por ejemplo, y como indica el título con el plural academias, la obra no es la transcripción más o menos pormenorizada de una academia dividida en cinco sesiones -que se corresponderían con los cinco «divertimientos» de la obra- sino que, en realidad, se trata de cinco academias, esto es, una por cada «divertimiento» o partes en las que se divide la obra. Esta división ya nos indica claramente que Castillo Solórzano se aleja drásticamente de uno de los principios básicos de todas las academias, esto es, su periodicidad, pues parece fácil estar de acuerdo con que una academia que tiene solo una sesión no es tal. Parece extraño, sin embargo, que un autor como Castillo, que, como hemos visto, ha crecido literariamente en las academias madrileñas, no conociera este precepto. Añádase que las academias literarios, de modo directo o indirecto, ya aparecían en dos obras anteriores a esta: Tardes entretenidas (1625) y Jornadas alegres (1626), y lo hará de nuevo en una posterior, Tiempo de regocijo (1635), como nos recuerda puntualmente King (1963: 127, 152 y 206, respectivamente). Por ello quizás debamos entender que lo que hace que las reuniones que Castillo nos relata en La Huerta de Valencia sean academias no es tanto su inexistente periodicidad, sino más bien la estructura y organización de cada una de ellas, estas sí, lo veremos, acordes con las de la institución que intentan imitar. Por lo demás -y sobre ello volveremos a tratar cuando hablemos de la cornice- provoca cierta confusión el hecho de que estas academias, estas cinco academias hasta cierto punto independientes, tengan siempre los mismos cinco miembros protagonistas y, pese a ello, no estén relacionadas entre sí, no sean, como hemos visto, cinco sesiones de una sola academia. La única solución que parece resolver todas estas contradicciones y paradojas es que el cambio espacial que se da en cada uno de los divertimientos en los que se divide la obra trasgrede el precepto académico de una única sede para las sesiones académicas. Sobre este aspecto volveremos también cuando hablemos de la estructura que engloba - o intenta englobar- cada una de las academias, divertimientos o capítulos.

Como sea, creo que estas y otras disidencias con respecto a la estructura canónica de las academias literarias justifican ciertas dudas sobre la cohesión estructural de la obra e, incluso, sobre su mismo título. La sospecha se ve reforzada en los preliminares o paratextos, en los que la obra viene siempre denominada simplemente como Huerta de Valencia, sin ningún añadido ulterior ${ }^{5}$; y, todavía

La «Aprobación» firmada por el Maestro Fray Vicente Gómez, quien dice «ha leído con atención este libro intitulado Huerta de Valencia»; la licencia eclesiástica firmada por el Vicario General 
más, en la dedicatoria «A los críticos», firmada por el propio autor, recibe idéntica denominación ${ }^{6}$. Debemos pensar, por lo tanto, que el añadido, pues de tal se trata, fue obra de Miguel Sorolla, el editor del libro y, de ser así, es fácil conjeturar que el mismo tenía una clara finalidad comercial. Digo esto porque parece evidente que la alusión a las «academias» en el título -y la alusión previa, «prosas y versos», como ya se ha indicado, parece tautológica para quien conozca la mezcolanza propia del género académico- puede tener una doble justificación, pero ambas con una clara finalidad lucrativa: conectar la obra que ahora se edita con las dos primeras de Castillo, las dos partes de Donaires del Parnaso, insertadas claramente como ya se ha indicado en la literatura de academia, alabadas por plumas tan prestigiosas como Lope o Tirso y que debieron tener bastante éxito comercial; o, tampoco debemos excluirlo, que el editor quisiera, ya desde el título, promover esta obra entre los muchos escritores y curiosos en general que participaban en las numerosas academias de dicha ciudad, presentándola como una obra que se insertaba con justa causa entre la literatura producida en las mismas. De estar en lo cierto, al editor valenciano debió parecerle no suficientemente atractivo el ya deíctico título puesto por Castillo, por lo que decidió añadir al localismo generalista del autor (Valencia) una clara alusión propagandística de uno de los fenómenos culturales más importantes de la ciudad, las academias, sabedor de que, con tal proceder, muchos de sus miembros serían también lectores de la obra.

No creo que esté en contradicción con la hipótesis anterior el que, al inicio de la obra, don Leonardo, uno de los cinco caballeros que participan en la narración, denomine a las reuniones programadas con tal término:

una Academia formada, no como las celebradas de Italia, sino un remedo suyo en cuanto a traer cada uno de los cinco, pues hacemos versos, los que se les repartieren al asumpto que se diere. (Castillo Solórzano 1944: 14)

Doctor Garcés dice que «ha visto y examinado el presente libro intitulado Huerta de Valencia», y, de la misma manera, la licencia civil firmada por Guillén Ramón de Mora expresa que «con particular atención y cuidado he leído este libro intitulado Huerta de Valencia» (Castillo Solórzano 1944: 1-3).

6 Y lo mismo ocurre con las composiciones laudatorias de distintos autores que preceden el texto. Así, don Sancho de Molina Cabeza de Vaca denomina el libro «Huerta peregrina»; Alonso Gerónimo de Salas Barbadillo habla de «huerta hermosa»; don Lorenzo de Soto y Vargas hablará del libro como de calidad «hortelana» y en la misma línea la composición de Felisarda Leonora denominará al autor «moderno hortelano»; el Licenciado Luys de Villalón, por su parte, dice que Valencia ha de agradecerle al autor tener «huertas dos» para terminar su pequeña composición repitiendo el calificativo del autor como «hortelano», y, por último, don Francisco de Tamayo y Porres, comparando de nuevo la huerta valenciana con la obra del autor, dice que «de vuestra Huerta admirada, / publica que es, la pintada, / mejor que la verdadera» (Castillo Solórzano 1944: 4-9) 
Quizás el editor valenciano de la obra también aludía a esto cuando, siempre por las razones indicadas, amplió el título, pero es justamente la aclaración «no como las celebradas de Italia» la que da a las narradas en el libro un marco de mera excusa narrativa en el que, sin mayores complicaciones, se puedan mezclar, justamente como dice el subtítulo, «prosas y versos». Debe añadirse a lo dicho, claro, las claras diferencias entre las academias italianas y las españolas, pues, como ha estudiado Egido (1990), mientras las primeras intentaban imitar sus homónimas griegas y latinas, dedicándose al estudio y promoción de las letras, las artes y las ciencias en general, las segundas tenían, con contadas excepciones, un carácter marcadamente lúdico, recreativo y social, y justamente ese tono festivo hacía que las poesías que en ellas se declamaban fueran, en efecto, acordes con el tono general de la reunión.

Es la poesía, pues, entendida como acabamos de explicar, la que inaugurará cada academia $\mathrm{y}$, a continuación de los versos, según la indicación de don Leonardo:

Y porque se le dilate más el tiempo, el que tuviere fiesta en su Alquería esté obligado a dar a los asuntos, quedándose con el trabajo, de más a más, de escribir una novela, o referirla de memoria, procurando que tenga su moralidad, porque se saque provecho de su artificio. Tras de esto, por remate de la fiesta, traeremos quien antes y después la alegre con la música. (Castillo Solórzano 1944: 14-15)

Por lo tanto y recapitulando, la estructura planificada de cada academia será iniciar todas las sesiones con música, seguir con poesía, añadir después una novela y, al final y si se tercia, concluir la reunión con un broche musical en perfecto paralelismo con sus inicios. Así, como acabamos de ver, es como don Leonardo, el académico de mayor autoridad, planifica en teoría las reuniones que habrán de celebrarse. Sin embargo, cuando vamos a ver en concreto, en cada uno de los divertimientos, capítulos o sesiones en los que se divide la obra no siempre se sigue el plan establecido. Quizás merezca la pena, por ello, enumerar aunque sea brevemente la composición de cada divertimiento, aprovechando la descripción para apuntar también la localización de la academia, aspecto este que, como se verá, no carece tampoco de interés.

El primer divertimiento se desarrolla en el jardín de la casa de don Leonardo, el académico de mayor edad y que, por tanto, inicia la academia. Comienza esta con una música -que, lógicamente, se refiere pero no se transcribe, lo que será constante en la obra-, para continuar con una novela corta, El amor por la piedad, a la que sigue de nuevo música e inmediatamente después una composición poética por cada uno de los académicos. De esta manera, el doctor Eusebio «a unos ojos glosó esta copla así», y en efecto la copla «Ojos, en cuya hermosura» se glosa con cuatro décimas que principian «Ojos de amor celebrados»; a continuación 
será Micer Hortensio el que desatará sus afectos con una liras «agradeciendo de parte de Cupido a la Muerte el haberse llevado a Nise, que le tiranizaba su Imperio»: «A ti, que incontrastable»; don Guillén, por su parte, nos deleita con un romance «A una sangría de una Dama, hecha por una caída», «Amor, rapaz y travieso». Por su parte don Leonardo declama un soneto dedicado «A una Dama muy flaca enterrada en una capilla muy ancha», «Este que ves, ;oh lince caminante!». La última composición de este primer divertimiento la ocupan las décimas que el Maestro Laurencio dedica a la «Descripción de la escolástica Miseria», «Describo edad floreciente». Habiendo, pues, declamado cada uno de los académicos una composición, tal y como preceptuaban las normas no escritas de la ficticia academia, la música sirve de cierre de la sesión y del divertimiento.

Corresponde al doctor Eusebio protagonizar el segundo divertimiento o jornada de la academia. Esta se desarrolla ahora en una sala baja de su alquería. Como en la primera sesión, una vez acomodados académicos y público, la sesión se abre con música, a la que sigue la narración de una novela corta, El soberbio castigado, a cuyo fin se entona de nuevo la música. Después, de acuerdo con cuanto ha sido previamente establecido, cada académico declama una composición: don Leonardo dedica unas décimas «A dos amantes muy rencillosos» («Si amor con pensión de abrazos»), mientras que don Guillén recita un soneto «Pintando jocosamente a la salida del Sol, aplicada a una Dama muy interesal» («Salió mosén Rubín por el Oriente»). Por su parte el Maestro Laurencio dedica un romance «Al susto que tuvo una dama por unas falsas nuevas que le dieron de ser muerto su galán» («La mentira y el engaño»), mientras que Micer Hortensio declama unas redondillas dedicadas «A una dama que al favorecer a su galán con un membrillo mordido le dexó dos dientes en él» («En más penoso cuidado»). Pone broche a las poesías el doctor Eusebio con la «Fábula jocosa de Acteón» («Érase que se era, empiezo»).

El tercer divertimiento tiene como narrador principal al Maestro Laurencio y se desarrolla en una estancia de su alquería. El esquema es el mismo que en los dos casos anteriores: música, novela corta (en esta ocasión la titulada El defensor contra sí), de nuevo la música y después una composición por cada académico. Inicia el doctor Eusebio con unas sentimentales décimas «A una resistencia de una dama, escrita en su nombre» («Afectos de Amor nacidos»), para continuar don Guillén con un romance satírico «A las cosas que suceden en estos tiempos» («Del mejor de los metales»). Micer Hortensio, por su parte, nos deleita con un filosófico soneto «A una mal lograda infancia, con anticipada discreción» («Sin que le deba a Flora sus favores») y se concluye con unas burlescas liras de don Leonardo dedicadas «A una pulga» («Animalejo inmundo») y unas endechas no menos cómicas del Maestro Laurencio «A una dama que vio a su galán abrazado con otra» («La hermosa Belisa»). 
El cuarto divertimiento, por su parte, se tiene en una galería de la alquería de Micer Hortensio, conductor de esta sesión. Como siempre, después de la música se introduce una novela corta, La Duquesa de Mantua en esta ocasión, y será la música de nuevo la que dé paso a las composiciones poéticas de cada académico. Don Guillén glosa la copla «Celia, llegar a tu cielo», con unas amorosas décimas que principian «Celia, desde mi prisión». El Maestro Laurencio, por el contrario, dedicará las suyas a la sátira, con una composición dirigida «A un médico que era juntamente engarzador de voluntades» («Insigne Academia, advierte»). De la sátira se pasa a lo burlesco con unas décimas del doctor Eusebio dedicadas «Al melindre de una dama vieja y fea» («Presumida Laura en quien») y un soneto de don Leonardo «A lo que siente una mujer cuando escucha amores de quien carece de dineros» («Sin gusto escucha la que advierte atenta»). Se termina, cambiando radicalmente el tono, con unas liras amorosas de Micer Hortensio dedicadas «A unos cabellos de una dama» («Navega el mar undoso»).

En el quinto y último divertimiento -que se desarrolla en lugar indeterminado de la alquería de don Guillén- la estructura habitual hasta ahora se modifica. De esta manera, las composiciones musicales e iniciales no sirven, como hasta aquí, para abrazar la novela corta que se inserta entre ellas, sino que ahora, por el contrario, son las composiciones poéticas de los académicos los que ocupan el lugar de aquella. De esta manera la sesión se abre con un romance del anfitrión, don Guillén, «A la hermosa boca de una dama» («Al que preside en los campos»), al que le sigue a continuación un epitafio de don Leonardo «A una amante sepultado por no publicar su amor» («Yace el que a vocación de una hermosura»). El Maestro Laurencio, por su parte, glosa la copla «Niña hermosa a quien adoro», con una décimas que inician «Amor, que es dulce prisión». Después aparecen dos composiciones burlescas: las «décimas yocosas» del doctor Eusebio dirigidas «A un pie pequeño herido de la lanceta de un mal sangrador» («Pie de Belisa, a quien dan») y un romance de Micer Hortensio en el que «Pinta unos amores yocosamente, en que es desdeñado el amante» («El vendado Dios, tan niño»). Al final de la sesión, como ya se ha indicado, aparece la obra de teatro El agravio satisfecho.

Pues bien, descritos sucintamente cada uno de las sesiones o «divertimientos» de los que se compone la obra, se debe ahora anotar algunas características de esta estructura narrativa. De esta manera, se debe empezar apuntando que en los dos primeros divertimientos, con don Leonardo y don Eusebio como narradores, la academia se abre con música cantada -que no se transcribe-, a la que sigue una novela, volviéndose después a los músicos -sin decirnos qué cantan-, e insertando a continuación cinco composiciones poéticas, una por cada miembro de la academia, para, como colofón, dejar de nuevo que suene la música, siempre como mera alusión que hace el narrador y sin referir nunca los versos cantados. Por el contrario, los divertimientos tercero y cuarto, que tienen al Maestro Laurencio y a 
Micer Hortensio respectivamente como narradores, ya presentan un leve cambio, pues se ha eliminado la intervención de los músicos que, como acabamos de ver, servía de colofón a la sesión académica. Pero son todavía mayores los cambios en el quinto y último capítulo, el confiado a don Guillén como narrador, pues la sesión la abren los músicos, dejando paso después a las consabidas cinco composiciones de los académicos y sirviendo de colofón al final de las mismas. Inmediatamente después se inserta no una novela corta, como en los cuatro casos anteriores, sino una obra de teatro, El agravio satisfecho ${ }^{7}$, adornada «con excelentes bailes y entremeses» que tampoco nos vienen referidos. Un final tan habitual como precipitado y abrupto cierra este quinto divertimiento y con él la obra.

Pues bien, si comparamos la cita anterior en la que se nos daba el esquema de la obra y su realización práctica en el texto, constatamos no pocas diferencias, algunas casi insignificantes, como la supresión de los músicos, pero otras de mayor importancia. Sin duda la que más llama la atención es la inserción de esta obra, $E l$ agravio satisfecho, en el último divertimiento. Es cierto que don Guillén, el narrador del mismo, intenta justificar la inclusión de la misma explicando que

Como por ser varia se llama hermosa la Naturaleza, he querido que esta fiesta lo sea de las que ha visto tan discreto auditorio, pues, en lugar de la Novela que me tocaba decir, les quiero divertir con una Comedia que he escrito. Esta representará la compañía que asiste aquí tan aplaudida desta Ciudad. (Castillo Solórzano 1944: 216)

Pero su intento es tan vano como tópico, porque si bien es cierto que la representación de obras dramáticas no estaba excluida de la poética de las academias, no lo es menos que su repentina aparición al final del libro parece señalar una inclusión un tanto forzada y desde luego, como hemos visto ya, no programada. Recuérdese en este sentido que en la obra contemporánea de la que aquí se estudia, el Lisardo enamorado, en el prólogo «Al lector» se anunciaba ya la publicación de la Huerta de Valencia, definiéndola como «libro de novelas», sin hacer la más mínima alusión al género dramático. La causa de este brusco cambio con respecto al programa original bien pudiera ser que a nuestro fecundísimo polígrafo se le hubieran agotado las novelas $\mathrm{o}-\mathrm{y}$ esto es lo más probable- que las que tenía las hubiera ya colocado en su siguiente obra. Recuérdese, en este sentido, que las aprobaciones de la Huerta de Valencia llevan fecha de enero de 1629, mientras que las de las Noches de placer son de febrero de 1631, y en esos dos años, además de las convulsas vicisitudes de su vida al servicio de la alta nobleza ${ }^{8}$, tuvo que tener tiempo para componer las doce novelas que componen su última colección citada.

\footnotetext{
$7 \quad$ Por lo demás inspirada en una novela corta cervantina, La fuerza de la sangre; véase Vaiopoulos (2010a, 2010b) y, sobre todo, las importantes observaciones que hace Escudero Baztán (2013).

8 Del año 1630 dice Juliá Martínez que fue para nuestro autor «tan rico en plácemes y tributos literarios como horro en bienes de fortuna; desaparecieron las herencias patrimoniales, pero
} 
La desorganización de la estructura presenta paralelo remedo en la relación entre sus partes. Como ya hemos visto, esta se basa en la división en cinco sesiones de una peculiar academia literaria que sirve como cornice o marco a la narración de las cuatro novelas y a la representación teatral de la última sesión. Cinco personajes protagonizan cada una de las sesiones, bien como narradores de la novela -los cuatro primeros divertimientos-, bien como introductor y presentador de la obra dramática. A su vez, estos cinco personajes participan como improvisados poetas en la parte reservada a la lírica en cada una de las cinco sesiones. Hasta aquí, enumerados someramente, los elementos que intentan dar cohesión a la obra. El intento, sobra decirlo, resulta inútil, y ello porque son infinitamente más y, sobre todo, más importantes, los que indican claramente la endeblez del entramado. Si analizamos la comitiva, más allá de la superficial y tópica descripción que se hace de cada uno de ellos al inicio de la obra, no hay ningún intento de personalización, de individualización, siendo absolutamente intercambiables ya como narradores de novelas - no hay ninguna relación entre lo narrado y el narrador-, ya como vates ocasionales. En ambos casos son meros soportes narrativos, excusas del -se adivinará ya- omnipotente autor, para dar rienda suelta a su afán literario. Tampoco se establecen, salvo las habituales y parcas líneas que impone el tópico, relaciones entre los narradores y los narratarios: la novela se narra y al acabar desaparecen ambos, pues no hay diálogo, preguntas o comentarios sobre la misma. La narración de cada novela, en efecto, no hace avanzar la trama general que las engloba, quizás porque esta, como ya se ha señalado, es tan endeble como artificial. Por su parte, tampoco hay ninguna relación entre las partes de cada sesión o divertimiento: las poesías que se declaman no sirven de glosa, comentario o añadido a la novela que acompañan, y, por ello, podrían ser fácilmente intercambiadas en su ubicación sin que la estructura general del relato y particular del capítulo se resintiera lo más mínimo.

Y, pese a ello, la poesía se puede definir como un elemento constante de la obra, pues aparece en los cinco divertimientos de la misma. Sus autores ficticios son cada uno de los cinco personajes que forman la academia y que, al principio de la obra, nos han sido presentados: don Leonardo, el más anciano, «había estudiado hasta saber con perfección la lengua latina y la Retórica, y de Historia lo bastante para hablar en cualquier conversación», si bien su principal actividad literaria parece ser la poesía; el doctor Eusebio, también de autoritaria madurez, era médico y filósofo, y a ratos perdidos dedicaba también su inteligencia a las Musas. Micer Hortensio, por su parte, es, pese a su juventud, un gran jurista y

surgieron los aplausos a granel» (pp. XIX-XX). En 1631, cuando muere don Luis Fajardo en Valencia, él ya no se encontraba en dicha ciudad, como testimonia su ausencia en las exequias el que fue su señor. Seguramente se encontraba ya en Barcelona sirviendo al hijo, don Pedro o, como sugiere Jauralde Pou (1979), hubiera realizado un breve viaje a Italia. 
también él en los ratos que le deja su estudio cultiva la poesía. Don Guillén, estudiante de «Artes y Filosofía», era, pese a su bisoñez, ya un consumado poeta y un aclamado músico; por último, el Maestro Laurencio, recientemente graduado en Teología, erudito también en letras humanas, había cultivado desde su juventud la poesía.

El tipo de poesía que vamos a encontrar en la obra nos viene anticipado por el narrador en la presentación de don Leonardo, cuando dice que este

hacía versos con cuidado, no con afectación que llegase a ser tenido por estos que llaman cultos, pienso que por ironía, porque si lo culto es lo que debemos tener por lo primoroso, lo opuesto a ello, tan mal entendido de tantos como cursado de muchos, más merece el nombre de inculto que otro; pues, con tan demasiado cuidado, ponen el afecto en su oscuridad y en ella misma se pierden ${ }^{9}$.

Se alude, claro está, a la conocida polémica gongorina, tomando parte con los que atacan al cordobés por su estilo, considerado, como dicen, el texto "oscuro".

Pero dejando esto de lado, podría pensarse que el establecimiento de una tipología de narrador para cada una de las partes, con las característica que acabamos de enumerar, llevara consigo, al menos para la poesía, una consecuente adscripción al mismo de un determinado registro poético, cuando no género. Nada de esto encontramos, sin embargo, cuando acudimos al texto. De esto modo, el docto don Leonardo y el teólogo Laurencio parecen gustar de la poesía satírica y/o burlesca, pues las cinco composiciones que declaman pertenecen a este género; por su parte, el doctor Eusebio, Micer Hortensio y don Guillén, por el contrario, alternan con naturalidad la musa jocosa y alegre con las más encendidas muestras de sentimiento amoroso, sin excluir, como Micer Hortensio, la poesía de temática filosófico-moral. Pero ya de lo dicho quedará claro que la temática preponderante en los textos poéticos es la satírico-burlesca, con diecisiete textos de los veinticinco que se incluyen; siete serán solo los amorosos y uno, como ya queda dicho, filosófico-moral. Ni uno solo de ellas, y el dato es importante, había aparecido antes impreso, sobre todo, como podría parecer lógico, en los Donaires.

De lo visto hasta aquí podemos extraer algunas conclusiones. Parece claro que la estructura interna del libro - la academia ficticia- está pensada para poder acarrear dentro de ella materiales literarios de muy diversa índole: novelas cortas, poesías de las más variadas temáticas y géneros e, incluso, una obra de teatro. De alguna manera, se sigue la línea iniciada por Salas Barbadillo y Tirso de Molina,

\footnotetext{
9 Parecidas palabras, pero ahora aplicadas a la novelística, podemos leer en el prólogo «Al lector» de su Lisardo enamorado, donde se nos dice que el estilo de la misma «no es tan cuidadoso que se acoja a esto que llaman culto, ni tan relevante que le ignore por oscuro el que le desea entender; porque no quiero que este libro se compre por inteligible; que estuviera a peligro de correr varias fortunas, hallando en él ignorancias apiñadas» (Castillo Solórzano 1947: 123).
} 
autores en los que las colecciones de novelas pasan a incluir otros componentes literarios, a menudo a partir de elementos académicos, de forma que estas colecciones acaban convirtiéndose en un género más amplio, que Piqueras Flores $(2016 ; 2017 ; 2018)$ ha denominado «colecciones de metaficciones». Parece claro, entonces, que es la variatio el norte que guía la disposición de los materiales literarios dentro de la obra, y es por ello fácil de deducir que dicha variedad busca, sobre todo, la aprobación de los lectores, con una obra total donde pueden encontrar todo aquello que el mercado editorial les ofrece. Pero por la misma razón, y a propósito de lo dicho sobre la sorprendente y no pensada introducción de la obra de teatro en la obra, parece también lógico deducir que la casi sobrehumana vena literaria de Castillo Solórzano encontraba en la estructura ofrecida por las academias literarias un campo fértil donde poder ubicar obras ya redactadas anteriormente o hechas para la ocasión, pero tanto en un caso como en el otro capaces de ofrecer al lector una experiencia literaria tan variada como divertida y amena.

\section{BIBLIOGRAFÍA CITADA}

Bonilla Cerezo, Rafael (2012). «Alonso de Castillo Solórzano: bio-bibliografía completa», Tintas. Quaderni di letterature iberiche e iberoamericane, 2, pp. 243-283.

Castillo Solórzano, Alonso de (1624). Donayres del Parnaso. Madrid: Diego Flamenco. (1625). Donayres del Parnaso. Segunda parte. Madrid: Diego Flamenco.

(1629). Lisardo enamorado. Valencia: Juan Crisóstomo Garriz; (1947) Lisardo enamorado. Prólogo y notas de Eduardo Juliá Martínez. Madrid: Biblioteca Selecta de Clásicos Españoles, Real Academia Española, Serie II, tomo III.

- (1944). Huerta de Valencia. Prosas y versos en las academias de ella. Edición de Eduardo Juliá Martínez. Madrid: Sociedad de Bibliófilos Españoles.

(1972). La Garduña de Sevilla. Edición y notas de Federico Ruiz Morcuende. Madrid: Espasa-Calpe, Clásicos Castellanos.

(1977). Sala de recreación. Edición, introducción y notas de Richard F. Glenn y Francis G. Very. Madrid: Editorial Castalia (Estudios de Hispanófila, 43).

- (2003). Donaires del Parnaso de Alonso de Castillo Solórzano. Edición, estudio y notas de Luciano López Gutiérrez [tesis doctoral]. Madrid: Universidad Complutense de Madrid .

EGIDO, Aurora (1990). «Una introducción a la poesía y a las academias literarias del Siglo de Oro». En Fronteras de la poesía en el Barroco. Barcelona: Crítica, 1990, pp. 115137. Antes en Estudios Humanísticos, Filología, VI (1984), pp. 9-26.

ESCUDERO BATZÁN, Juan Manuel (2013). «Reescrituras dramáticas áureas de La fuerza de la sangre de Cervantes». Anales Cervantinos, XLV, pp. 155-174.

GioRgi, Giulia (2014). «Alonso de Castillo Solórzano reescritor de sí mismo: algunas notas sobre los Escarmientos de amor moralizados y el Lisardo enamorado». Edad de Oro, XXXIII, pp. 257-266. 
Jauralde Pou, Pablo (1979). «Alonso de Castillo Solórzano, Donaires del Parnaso y la "Fábula de Polifemo"». Revista de Archivos, Bibliotecas y Museos, LXXXII, pp. 727-766.

Kennedy, Ruth L. (1968). «Pantaleón de Ribera, 'Sirene', Castillo y Solórzano and the Academia de Madrid in Early 1625». Hommage to John M. Hill. Bloomington: Indiana University Press, pp. 189-200.

KING, Willard F. (1960). «The Academies and Seventeenth-century Spanish literature». Publications Modern Language Association, LXXV, pp. 367-376. (1963). Prosa novelística y Academias literarias en el siglo XVII. Madrid: Real Academia Española (Anejos del Boletín de la Real Academia Española).

MAs I Usó, Pascual (1991). Justas, Academias y Convocatorias literarias en la Valencia Barroca (1591-1705). Teoría y práctica de una convención [tesis doctoral]. Valencia: Universidad de Valencia.

(1994). «Academias ficticias valencianas durante el Barroco», Criticón, 61, pp. 47-56.

Piqueras Flores, Manuel (2016). «Alonso J. de Salas Barbadillo y las colecciones de metaficciones áureas», Castilla. Estudios de Literatura, 7, pp. 794-811.

- (2017). «De las colecciones de novelas cortas a las colecciones de metaficciones, un análisis de Fiestas de la boda de la incasable malcasada de Salas Barbadillo», eHumanista, 35, pp. 454-474.

(2018) (en prensa). La literatura en el abismo: Salas Barbadillo y las colecciones de metaficciones, Vigo: Academia del Hispanismo.

SÁnCHEZ, José (1961). Academias literarias del Siglo de Oro español. Madrid: Gredos.

VAiopoulos, Katerina (2010a). De la novela a la comedia: las "Novelas ejemplares" de Cervantes en el teatro del Siglo de Oro. Vigo: Academia del Hispanismo.

(2010b). «La tradición narrativa en el teatro español del Siglo de Oro. El caso de las Novelas ejemplares de Cervantes». Natalia Fernández (ed.), "Como en la antigua, en la edad nuestra”. Presencia de la tradición en la literatura española del Siglo de Oro. Barcelona: Universidad de Barcelona, Prolope, TC/12, pp. 83-119.

Velasco Kindelan, Magdalena (1983). La novela cortesana y picaresca de Castillo Solórzano. Valladolid: Institución Cultural Simancas.

Recibido: 2-9-2017

Aceptado: 30-10-2017

Edad de Oro, XXXVI (2017), pp. 45-58, ISSN: 0212-0429 
HuERTA DE VALENCIA: ENTRE LA COLECCIÓN DE NOVELAS Y EL CANCIONERO DE ACADEMIA

Resumen: Huerta de Valencia. Prosas y versos en las Academias della (1629) se publica en un momento importante y significativo de la carrera editorial y literaria de Castillo Solórzano, cuando la experimentación con nuevas formas narrativas le lleva sobre todo al camino de la sinergia entre las mismas, aspirando así a ofrecer un producto editorial donde el lector pueda encontrar todas las formas literarias a su alcance: poesía, narrativa, teatro. En este trabajo justamente se intenta analizar esta confluencia genérica tratando de dar un sentido literario y editorial al proficuo empeño del autor.

PALABRAS ClAVE: géneros literarios, novela, teatro, poesía.

HuERTA DE VALENCIA: BETWEEN THE COLLECTION OF NOVELS AND THE ACADEMY CANCIONERO

ABstract: Huerta de Valencia. Prosas y versos en las Academias della (1629) is published in an important and meaningful moment of the publishing and literary career of Castillo Solórzano, when experimentation with new narrative forms leads him especially to produce a synergic effect of them, running to offer an editorial product where the reader can find all the literary forms at his disposal: poetry, narrative, theatre. In this work, we try to analiyze this essential confluence by trying to give a literary and editorial sense to the author's worthwhile commitment.

KEYWORDS: literary genres, novel, theatre, poetry. 


\section{EDAD DE ORO}

Revista de Filología Hispánica XXXVI

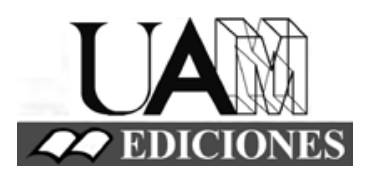




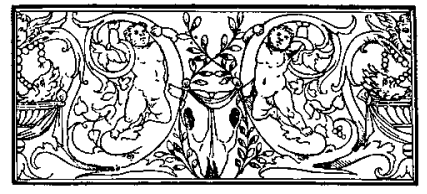

\section{Edad de Oro. Revista de Filología Hispánica}

ISSN: 0212-0429

Dirección:

Teodosio Fernández

Secretaría y edición:

José Ramón Trujillo

Consejo de redacción:

Manuel Piqueras

Blanca Santos

Admisión de originales:

María Jesús Zamora

Edad de Oro

Departamento de Filología Española

Universidad Autónoma de Madrid

28049 Madrid (España)

Tfno.: +0034914974090

correo: mariajesus.zamora@uam.es

Distribución, suscripción y venta:

Servicio de Publicaciones de la UAM

Universidad Autónoma de Madrid

28049 Madrid (España)

Intercambio de publicaciones:

Biblioteca de la Facultad de Filosofía y

Letras (UAM)

Universidad Autónoma de Madrid

28049 Madrid (España)
Comité científico internacional:

Carlos Alvar (Univ. de Ginebra)

Ignacio Arellano (Univ. de Navarra)

Javier Blasco (Univ. de Valladolid)

Alberto Blecua (UAB)

Jean Canavaggio (Univ. de París X)

Laura Dolfi (Univ. de Turín)

Aurora Egido (Univ. de Zaragoza)

Víctor García de la Concha (RAE)

Luciano García Lorenzo (CSIC)

Joaquín González Cuenca (Univ. de

Castilla-La Mancha)

Agustín de La Granja (Univ. de Granada)

Begoña López Bueno (Univ. de Sevilla)

Michel Moner (Univ. de Toulouse III)

Joan Oleza (Univ. de Valencia)

Alfonso Rey (Univ. de Santiago)

Lina Rodríguez Cacho (Univ. de Salamanca)

Leonardo Romero Tobar (Univ. de Zaragoza)

Aldo Ruffinatto (Univ. de Turín)

Lía Schwartz (City University of New York)

Han colaborado en este volumen:

Departamento de Filología Española (UAM)

Facultad de Filosofía y Letras (UAM)

Edad de Oro se recoge, entre otras, en las siguientes bases de datos: SCOPUS, MLA Database, HLAS, Latindex, PIO-Periodical Content Index, ISOC, Dialnet, MIAR, ERIH Plus, DICE, Sumaris CBUC, Ulrich's. Se encuentra evaluada en CIRC: A; MIAR difusión ICDS live 2016: 10.0; INRECH; SCImago Journal \& Country Rank: H Index 3, SJR SCImago Journal \& Country Rank 0,1, Q4; RESH índice de impacto: 0.041; ERIH: A INT1; Carhus Plus+2014: C. 